\title{
Mycobiome Transplant Increases Resistance to Austropuccinia psidii in an Endangered Hawaiian Plant
}

\author{
M. K. Chock, ${ }^{1,2, \dagger}$ B. K. Hoyt, ${ }^{1}$ and A. S. Amend ${ }^{1}$ \\ ${ }^{1}$ Department of Botany, University of Hawai'i at Mānoa, HI 96822 \\ ${ }^{2}$ Department of Integrative Biology, University of California, Berkeley, CA 94720 \\ Accepted for publication 18 February 2021.
}

\section{ABSTRACT}

The accelerated global movement of plant pathogens has become a substantial threat to rare and endangered plants. Although application of synthetic pesticides on endangered plants is often necessary to control disease in greenhouse settings, these chemical treatments degrade the leaf microbiome. This reduction in diversity can eliminate foliar microbes that are essential for pathogen resistance, making plant hosts more susceptible to disease once outplanted in the wild. Beneficial microbes that naturally occur in plant tissue are a resource that is quickly gaining traction as a viable means to increase plant fitness and pathogen resistance in both agricultural and wild habitats. This is of particular interest for threatened and endangered wild plant populations with limited genetic variation where breeding for resistance is not possible. In this experiment, we tested the effectiveness of microbial inoculations to inhibit the fungal pathogen Austropuccinia psidii, which is currently threatening the critically endangered Hawaiian
Eugenia koolauensis with extinction. Using molecular and culture-based methods, we characterize foliar fungal communities of Myrtaceous hosts resistant to A. psidii and introduced these diverse fungi into the microbiome of E. koolauensis leaves. Our results indicate that transplanting an intact mycobiome community is more effective at reducing foliar disease resistance when compared with single-fungalspecies inocula. These findings demonstrate the potential of whole-microbiome transplants as a powerful tool to inducing disease resistance and enhancing plant health within a conservation context.

Keywords: conservation, ecological restoration, ecology, ecosystems, endophytes, Eucalyptus, forestry, management, microbiome, mutualism, mycology, Myrtaceae, Myrtle rust, natural habitats, Ohia rust, plant pathology, rhizosphere and phyllosphere
The accelerated global movement of plant pathogens is a substantial threat to forest health and the diverse flora they harbor (Boyd et al. 2013; Roy et al. 2014). Although efforts to mitigate the spread of introduced pathogens have, in some cases, been successful with phytosanitary policies, it is difficult to control these pathogens once they become established within native forests (Wingfield et al. 2015). When native floras are particularly susceptible, alien pathogen introductions can result in a rapid decline or local extinction of plant populations. Fortunately, many tools to

†Corresponding author: M. K. Chock; kamalani.chock@berkeley.edu

Funding: Support was provided to A. S. Amend by National Science Foundation Division of Environmental Biology grant number 1255972 and to M. K. Chock by the Hau'oli Mau Loa Fellowship Program.

*The $\boldsymbol{e}$-Xtra logo stands for "electronic extra" and indicates that a supplementary figure and supplementary tables are published online.

The author(s) declare no conflict of interest

(C) 2021 The American Phytopathological Society mitigate pathogen disturbances are being developed. Outplanting of genetically diverse individuals is a common practice for plants susceptible to introduced pathogens and has been shown to improve overall population resilience across diverse biotic and abiotic conditions (Frankham 2003; Iriondo et al. 2008). Most recently, advances in genomic technologies and resources have led to the development of genetic based strategies (e.g., selective breeding and transgenic introgression) to increase pathogen resistance in wild species threatened by introduced pathogens (Newhouse et al. 2014). However, critically endangered plant species are often unable to utilize these disease management practices due to their inherent deficiency in genetic variation and lack of support and resources for more expensive and time-consuming techniques (Ellstrand and Elam 1993). Conservation of endangered plant species threatened by pathogens poses a unique problem that often is remediated only through regular chemical application in small greenhouse populations. Developing innovative and effective, long-term disease control methods will be imperative in preventing the extinction of endangered plants threatened by introduced pathogens.

An overlooked disease management approach for endangered plant conservation is the use of microbial biocontrols. A growing 
body of literature suggests that foliar endophytic fungi (FEF), microfungi inhabiting the leaf tissue of all plants, are an integral component to the modification of plant disease severity (Busby et al. 2017). There is increasing evidence that FEF decrease plant pathogens directly (e.g., hyperparasitism, antibiosis, and competition) and indirectly (e.g., induced resistance and increased plant health) during pathogen invasion (Aly et al. 2011; Arnold et al. 2003; Christian et al. 2017; Heydari and Pessarakli 2010). Although there is a multitude of studies that have assessed the effectiveness of native FEF in controlling plant disease within agricultural settings, few have looked at their potential as a disease biocontrol in natural habitats, and especially with endangered species (Busby et al. 2016; O'Hanlon et al. 2012; Parratt and Laine 2016; Zahn and Amend 2017). The introduction of beneficial FEF into endangered plant species could not only provide an alternative to environmentally harmful synthetic pesticides in greenhouse populations but also help establish a robust foliar microbiome that maintains disease resistance once plants are reintroduced into their natural habitats.

Austropuccinia psidii (Basidiomycota; Pucciniales) is an obligate fungal rust pathogen that has become a global presence due its unusually large host infection range (445 known species within 73 genera of the family Myrtaceae) and ability to produce millions of wind-dispersed spores (Carnegie and Giblin 2020; Soewarto et al. 2019). A. psidii has caused considerable declines in many commercially and ecologically important plant species around the world. Some plants are currently threatened by extinction (e.g., Melaleuca spp., Rhodomyrtus psidioides, and Rhodamnia rubescens) due to the introduction of the rust (Carnegie et al. 2016; Pegg et al. 2018). One such species whose existence is compromised by the introduction of A. psidii is the endemic and critically endangered Hawaiian tree, Nioi (Eugenia koolauensis). In April 2005, a single genotype of the rust, recently designated as the "pandemic biotype", was introduced to Hawai'i and quickly spread throughout the island chain in a few months (Loope et al. 2008; Stewart et al. 2017; Zhong et al. 2011). A. psidii is especially virulent on E. koolauensis (Loope 2010). Today, A. psidii poses a critical threat to the remaining approximately 99 mature trees (11 populations) that exist in managed conservation enclosures (U.S. Fish and Wildlife 2011). Through defoliation of young leaves and destruction of sexual structures, $A$. psidii can prevent highly susceptible species from reproducing sexually or vegetatively in the wild (Glen et al. 2007). The culmination of these factors qualified E. koolauensis to be recently listed on the International Union for Conservation of Nature and Natural
Resources red list of threatened species as a critically endangered species (Keir 2018). Although there have been attempts to repopulate this species in their native habitat, recent efforts have been unsuccessful (M. Garma, personal communications). It is possible that the need for consistent application of fungicides on cultivated $E$. koolauensis reduces the presence of beneficial FEF, ultimately disrupting host ecological function and further promoting susceptibility to $A$. psidii once trees are outplanted in the wild (Karlsson et al. 2014). By establishing a leaf microbiome with beneficial FEF in a greenhouse setting, we hope to increase disease resistance to $A$. psidii in cultivated individuals of E. koolauensis that persists once outplanted in the wild.

The main objective of this work was to assess the efficacy of introducing wild-collected axenic FEF cultures and a whole FEF community on increasing E. koolauensis resilience toward A. psidii. We accomplished this by first identifying FEF that potentially interact with A. psidii within the leaves of resistant hosts, then evaluating their antagonistic potential within E. koolauensis leaves. Exploration of FEF antagonists was prompted by preliminary scanning electron microscopy (SEM) of infected Rose apple (Syzygium jambos) leaves, which revealed hyphae of a possibly hyperparsitic fungi coiled around $A$. psidii urediniospores (Fig. 1A) and another filamentous fungus that colonizes $A$. psidii pustules shortly after sporulation (Fig. 1B). Although these observations suggest that some FEF isolates will exhibit strong antagonism toward A. psidii, we hypothesize that the introduction of a whole FEF community also provides protection toward $A$. psidii, owing to the diversity of disease inhibiting mechanisms that are commonly observed in wild FEF communities (Busby et al. 2016).

\section{MATERIALS AND METHODS}

Experimental overview. The experiment tested the effects of FEF modulation on the E. koolauensis-A. psidii pathosystem by applying isolated FEF spore slurries to E. koolauensis seedlings. FEF were collected from mature leaves of wild healthy relatives of E. koolauensis (S. jambos, E. reinwardtiana, and Metrosideros polymorpha). These plant relatives overlap in habitat range and are known hosts of $A$. psidii, with variable degrees of susceptibility (Carnegie and Lidbetter 2012; Langrell et al. 2008; Loope 2010). The selection of these taxa for isolation of FEF was not due to their phylogenetic relatedness or species-specific resistance but, rather, for their asymptomatic leaf conditions in the presence of $A$. psidii
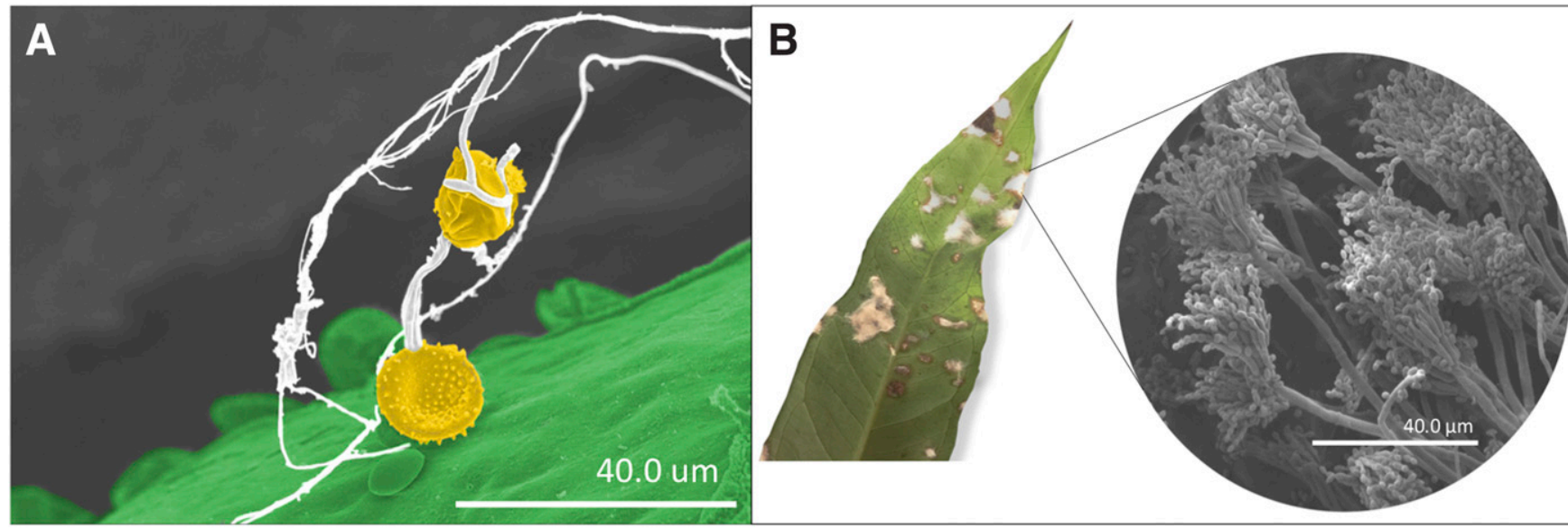

Fig. 1. Scanning electron microscopy of filamentous fungi interacting with Austropuccinia psidii urediniospores and pustules. A, Hyperparasitic filamentous fungi (white) wrapping and penetrating $A$. psidii urediniospores (yellow) on the leaf surface (green). B, White filamentous fungal growth, possibly Aspergillus spp., in A. psidii pustules on Syzygium jambos leaves 14 days after pathogen inoculation and incubation. 
spores (nearby inoculum sources), increasing the chance of isolating FEF that directly interact and possibly inhibit $A$. psidii. A similar reasoning was used to justify the use of wild $S$. jambos leaves for the leaf homogenate treatment. After developing an FEF isolate library, specific microbial taxa were chosen for inocula based on their known inhibitory activity to rust pathogens.

As an endangered species, the availability of E. koolauensis germplasm was limited, allowing for 12 individuals for each treatment. In total, 84 E. koolauensis plants were exposed to fresh A. psidii spores, $72 \mathrm{~h}$ after FEF introductions. Disease severity was observed after 14 days (average time for pustule formation and sporulation). To control for disease reduction attributed to FEF and not to phytochemical or bacterial components present in the homogenate, a control treatment was produced by filtering the leaf homogenate through a $2-\mu \mathrm{m}$ filter and microscopically verifed for the presence of fungal spores.

Isolation. FEF used in this study were isolated from the leaves of wild native and naturalized Hawaiian Myrtaceous plants, including M. polymorpha, S. jambos, and E. reinwardtiana, across the island of O'ahu, Hawai'i, U.S.A. Leaves were washed under distilled water and single 1-cm-diameter leaf disks were excised from collected leaf samples. Leaf disks were then surface sterilized in a $70 \%$ ethanol bath for $2 \mathrm{~min}$ and $1 \%$ sodium hypochlorite for $2 \mathrm{~min}$, then rinsed in a sterile water bath for $1 \mathrm{~min}$. Sterilized leaf disks were placed on $1 \%$ malt extract agar (MEA) media and incubated for 30 days or until extensive colony growth of endophytes was obtained (Schulz et al. 1993).

In addition to single plate leaf disk isolations (fragment plating), a subset of $S$. jambos leaves also used in the leaf homogenate was used to extract FEF via dilution-to-extinction culturing, which is known to increase culturable species diversity (Collado et al. 2007). These isolates represented culturable FEF that may also exist in the leaf homogenate treatment. Leaves were homogenized in sterile water $(400 \mathrm{ml})$ for $2 \mathrm{~min}$ and passed through a sterile filter assembly with a $100-\mu \mathrm{m}$ filter. The homogenate was then optimized by single-plate serial-dilution spotting and plated on 1\% MEA $(100 \mu \mathrm{l})$. Leaf disks and 96-well plates were incubated in darkness at $25^{\circ} \mathrm{C}$.

To isolate FEF residing within the urediniospore pustules of infected wild plant leaves, pustule formations were excised from infected leaves using sterile scissors and attached to the lid of Petri dishes containing MEA. Petri dishes were agitated to release FEF residing within the pustules. Petri dishes were incubated in darkness at $25^{\circ} \mathrm{C}$ to produce mixed culture plates. After 1 week, established FEF colonies were separated and transferred from mixed culture dishes into separate Petri dishes. After 30 days, isolates were grouped into 26 morphologically distinct groups and maintained in culture until plant inoculations.

Sequencing and phylogenetic analysis. Representative morphotypes were further delineated through Sanger sequencing of the internal transcribed spacer (ITS)1-28S region of the ribosomalencoding DNA using primers ITS1-F (3'-CTTGGTCATTTAGAG GAAGTAA-5') (Gardes and Bruns 1993) and TW13 (5'-GGT CCGTGTTTCAAGACG-3'). Purification and sequencing of PCR products were performed by GENEWIZ facilities (South Plainfield, NJ, U.S.A.) using an ABI Prism 3730xl DNA Analyzer. Sequences were submitted to GenBank's Basic Local Alignment Search Tool (https://www.ebi.ac.uk/blastall/nucleotide.html) and genus names were assigned based on E-scores ( $=0$ ), percent identity ( $\geq 98 \%)$, and consistency of query cover with sequences from the curated NCBI type strain database (BioProject: PRJNA177353). For the purpose of this work, morphotypes are considered as putative species. The accession number of sequences deposited to GenBank are listed in Table 1.

FEF selected for inoculation experiments, described in the section below, were further verified through phylogenetic analysis. Multiple sequence alignment of ITS genes was performed using Clustal
Omega (Sievers et al. 2011) and further revised and trimmed using Jalview version 2.11.1 (Waterhouse et al. 2009). The aligned sequences, including those of previous studies obtained from GenBank, were manually adjusted when necessary. Gaps and ambiguously aligned nucleotide positions were excluded from the datasets. Phylogenetic trees were constructed using the maximum-likelihood method in R (version 4.0.12) under the GTR + I model of evolution with 100 bootstrap replicates, using packages ape version 5.4-1 (Paradis and Schliep 2019) and ggtree version (Yu et al. 2017).

FEF selection and spore suspension preparation. Of the 26 isolates, we selected 4 FEF for inoculation experiments based on their potential antagonistic behavior to A. psidii as reported in previous literature (Høyer et al. 2019; Moricca and Ragazzi 2008; Moricca et al. 2005). Two isolates of Clonostachys rosea isolates were derived from either leaf tissue (C. rosea [Leaf]) or rust pustules (C. rosea [Rust]) to evaluate within-species differences based on origin of habitat. This subset of endophytic fungi was transferred to 100 -mm Petri dishes with $2 \%$ potato dextrose agarose media until they colonized the entire Petri dish. Dishes were then flooded with $10 \mathrm{ml}$ of sterile water and mycelia and propagules were dislodged using a sterile glass spreader. The spore suspensions were transferred into a sterile beaker and held in a solution of $0.1 \%$ Tween 20 (SigmaAldrich) at $4{ }^{\circ} \mathrm{C}$ until inoculation. Spore concentration was standardized using a hemocytometer at approximately $8 \times 10^{5}$ spores $/ \mathrm{ml}$.

Leaf homogenate preparation. Healthy $S$. jambos leaves $(50 \mathrm{~g})$ were collected as inoculum and surface sterilized similarly to the leaf disks. Leaves were then blended into tiny fragments with $400 \mathrm{ml}$ of sterile water for $2 \mathrm{~min}$. Using a sterilized vacuum filter assembly, the blended leaf homogenate was drawn through a $100-\mu \mathrm{m}$ filter to effectively remove larger particles and leaf matter. The filtrate was then mixed with $100 \mathrm{ml}$ of $0.05 \%$ Tween 20 and stored at $4{ }^{\circ} \mathrm{C}$ until use. A leaf homogenate without fungal spores (referred to as "Leaf homogenate + No FEF") was included as a treatment to control for leaf homogenate effects attributed to FEF rather than phytochemical or nonfungal microbial components. This was accomplished by further filtering the leaf homogenate filtrate through a $2-\mu \mathrm{m}$ filter (Grade $602 \mathrm{~h}$ ) to remove FEF spores, and mixing with $100 \mathrm{ml}$ of $0.05 \%$ Tween 20 before application.

Rearing of $\boldsymbol{E}$. koolauensis. Juvenile E. koolauensis plants were propagated by the O'ahu Army Natural Resources Program (OANRP). Due to rapid decline in wild populations, OANRP maintains a living collection of cuttings and clones of E. koolauensis from multiple populations to maintain genetic material. Limited germplasm availability made maintaining genetic uniformity difficult within this experiment. In an effort to control for genetic variation among $E$. koolauensis plants, all plants used in the experiment were derived from an individual tree (cuttings and seed) sourced from the U.S. Army Kahuku Training Area, Pūpūkea forest reserve (782 acres). Cuttings and seed were randomly distributed across treatments. Plant material was transported to the St. John Plant Science Laboratory (University of Hawai'i, Mānoa), repotted in 8-cm pots with soilless medium (Sunshine number 4; SunGro Horticulture, Agawam, MA, U.S.A.), and acclimated to a shaded and partially enclosed environment $\left(24^{\circ} \mathrm{C}\right)$ until inoculation. This growing environment was chosen due to optimal growing conditions. Plants were hand watered with distilled water daily, excluding weekends.

E. koolauensis inoculation. Twelve E. koolauensis plants were randomly selected for each treatment $(n=12)$ and inoculated with one of the four spore suspensions (Bionectria ochroleuca, Cladosporium cladosporioides, Clonostachys rosea [Leaf], and C. rosea [Rust]), the filtrated leaf homogenate, the leaf homogenate with no fungal spores (Leaf homogenate + No FEF), or a treatment with just A. psidii spores (Rust Only) (Supplementary Table S1). A "No rust + No FEF" treatment group was included to control for latent rust spores on 
E. koolauensis leaf tissue. This treatment consisted of sterilized water with no rust, no leaf homogenate, and no single-isolate spore introductions. All treatments were applied using a sterile hand sprayer (H.D. Hudson, Lowell, MI, U.S.A.) across the entirety of the plant $(n=12)$ following established methods (Zahn and Amend 2017). These applications occurred $72 \mathrm{~h}$ prior to A. psidii inoculation to encourage successful establishment of endophytes in E. koolauensis leaf tissue (Filonow et al. 1996). A. psidii urediniospores collected from wild $S$. jambos leaves were maintained at $-40^{\circ} \mathrm{C}$ until application. To prepare the inoculum, spores were placed in a suspension with $0.05 \%$ Tween 20 and sprayed across the entirety of each plant. Spore concentration was standardized using a hemocytometer at approximately $8 \times 10^{5}$ spores $/ \mathrm{ml}$. Following application of $A$. psidii spores, plants were placed in $100 \%$ humidity and darkness for $24 \mathrm{~h}$ to initiate $A$. psidii spore germination and appressorium formation. Following this period, a randomly selected branch with new growth was tagged with a sterile twist tie for future disease assessment. New growth was used for assessment to prevent substantial interactions with FEF present before inoculum introduction. Plants were then moved to an outside area and grown at $24^{\circ} \mathrm{C}$ under $8 \mathrm{~h}$ of light. Susceptible plants begin to show visible pustule formations 12 days postinoculation (Junghans et al. 2003). According to standard A. psidii assessment procedures, the youngest three leaves of each tagged branch were collected for disease assessment 14 days postinoculation (Junghans et al. 2003).

Analysis of disease severity. Samples were imaged using a digital camera (Canon EOS Rebel T7i). Images were then processed using the imaging software ImageJ version 2.0.0. Using the ImageJ plugin Trainable Weka segmentation, supervised image segmentation was used to disseminate and classify the leaf, rust, and background (Arganda-Carreras et al. 2017). Images were then converted to an RGB image color scheme using the ImageJ plugin Color Counter and the percentage of the leaf area damaged by the rust (e.g., pustules and necrotic tissue) was quantified.

Statistical analysis. Data analyses were accomplished using R, version 3.5.1 (R Core Team 2013). A one-way analysis of variance was performed with six levels across six independently generated treatments. Treatment groups included No rust + No FEF, Rust Only, Leaf homogenate, Leaf homogenate + No FEF, Cladosporium cladosporioides, B. ochroleuca, Clonostachys rosea (Rust), and $C$. rosea (Leaf). Post hoc comparisons using the Tukey

TABLE 1

Foliar endophytic fungi isolate identification, occurrence, and distribution based on host species and whether derived from leaf tissue or rust pustules

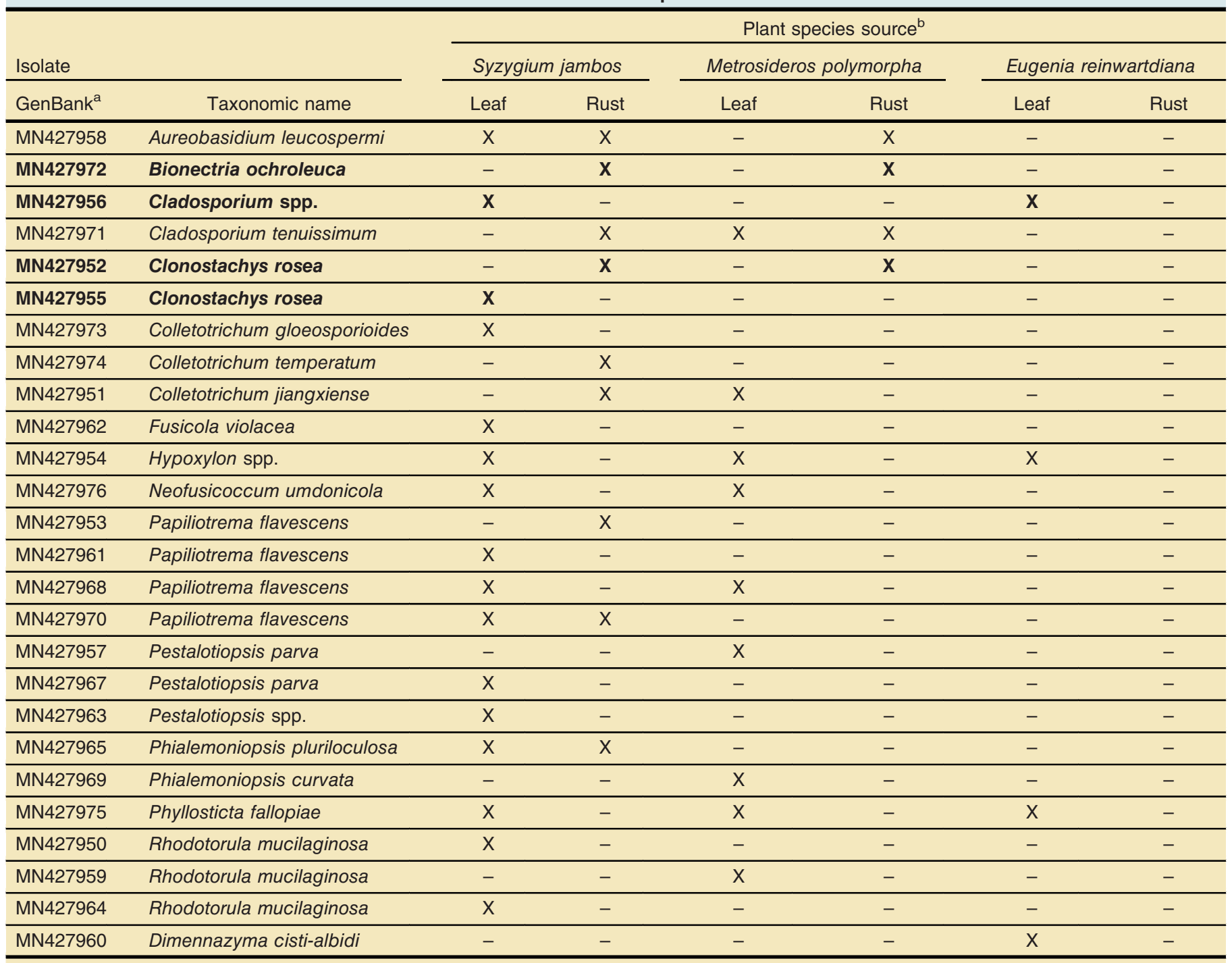

\footnotetext{
a GenBank accession number.

${ }^{\mathrm{b}}$ Leaf $=$ leaf tissue, Rust $=$ rust pustule, and $\mathrm{X}=$ presence in specified source. Data in bold indicate isolate was included in the inoculation experiment.
} 
honestly significant difference test verified significant differences between treatments. Treatments were considered significant at a $P$ value $<0.05$. Additionally, the standardized mean difference (Cohen's d) was calculated via unpaired $t$ tests and subsequently used to evaluate the efficacy of treatments against the shared control Rust Only within a $95.0 \%$ confidence interval. Values of $d>$ $0.2,0.5,0.8$, and 1.0 represent nominally small, medium, large, and very large effects, respectively (Gurevitch and Hedges 2001). These calculations were used to validate $P$ values and provide a better comparative representation of treatment effects when plotted. Graphs were plotted in $\mathrm{R}$ using the packages ggplot2 version 3.1.0 (Wickham 2009) and DABEST version 0.2.2. (Ho et al. 2019).

\section{RESULTS}

Identification of FEF. We identified 26 FEF taxa that were isolated from wild-collected leaves of two native and one naturalized Myrtaceae species: M. polymorpha, E. reinwardtiana, and S. jambos respectively (Table 1). In all, 3 of the 26 FEF were present across all plant species: Phyllosticta capitalensis, Cladosporium cladosporioides, and Eurotiomycetes spp. In total, $20 \mathrm{FEF}$ isolates were obtained from leaf tissue alone, while 11 distinct species were identified from within rust pustules of infected leaves. The majority of isolates were derived from $S$. jambos leaf tissue, likely because these plants were more accessible, thus allowing higher sampling frequency of this particular plant species. No isolates were obtained from infected E. reinwardtiana pustules due to the lack of available infected $E$. reinwardtiana leaves at the time of the experiment. Although isolation via serial dilutions provided a high sample number (768 microplate wells), cultures were primarily dominated by common FEF taxa, including Aureobasidium leucospermi, C. cladosporioides, C. tenuissimum, Colletotrichum gloeosporioides, Papiliotrema flavescens, and Rhodotorula mucilaginosa. Single-leaf disk inoculations made up 22 of the 26 identified FEF taxa while serial dilutions made up 6 of the 26 taxa. Due to the low diversity yield, isolation via serial dilution may benefit from more selective agar media.

Based on phylogenetic analysis using the ITS marker (25 sequences and 1,200 characters), with Austropuccinia psidii to root the tree, the four selected FEF were classified into two distinct clades: Cladosporium and Clonostachys (Supplementary Fig. S1). Low bootstrap values $(>70)$ near the tips of the tree perpetuated ambiguity of the Cladosporium sp. identity used in the study. This suggests that a more succinct identification of this isolate will require inclusion of longer or more diverse diagnostic genetic markers.

Disease development. Reduction of $A$. psidii pustule formation (measured via percent leaf area infected) on E. koolauensis leaves varied significantly among treatments $(\mathrm{df}=88, F=9.727, P<0.001)$ (Table 2). Although there were no observable rust-induced lesions on No rust + No FEF plants, a $0.8 \%$ disease severity (DS) was evaluated by the trainable segmentation machine-learning algorithm. This effectively provided an error margin for the image analysis $( \pm 0.8 \%)$ and verified the absence of latent $A$. psidii spores on E. koolauensis leaf tissue $(P<0.001)$. The Rust Only treatment functioned as a shared threshold or control among treatments to compare their effects on E. koolauensis disease severity (DS $=54 \%$ ).

Three of the four FEF spore suspension treatments-C. rosea (Rust), B. ochroleuca, and C. cladosporioides - had no discernable effect on $A$. psidii pustule formation (DS $=41 \%, P=0.131$; DS = $50 \%, P=0.599$; and (DS $=57 \%, P=0.811$, respectively) when compared with Rust Only (Fig. 2). These findings were also reflected in the small magnitude of effect sizes, generated as standardized mean differences $(d)$, of the three treatments individually paired with the shared control group, Rust Only $(d<0.5)$ (Supplementary Table S2).
Clonostachys rosea, isolated from leaf tissue, reduced average A. psidii pustule formation compared with the Rust Only treatment, though results were not significant $(\mathrm{DS}=36 \%, d=-0.845$, $P=0.088$ ) (Table 2). Similarly, the Leaf homogenate + No FEF treatment had a marginal but statistically insignificant effect on $A$. psidii pustule reduction (DS $=35 \%, d=-0.924, P=0.075$ ). The Leaf homogenate treatment, derived from wild collected $S$. jambos leaves, was the only treatment to significantly decrease A. psidii pustule formation (DS $=20 \%, d=-1.377, P=0.001$ ).

\section{DISCUSSION}

Traditional methods of ex situ disease management for endangered plant species have focused on chemical fungicide treatment. Today, conservationists and land managers are moving toward control methods that are more economical, less environmentally taxing, and offer longer-term solutions. It is increasingly recognized that successful application of these methods will require careful consideration of all aspects of the phytobiome, including the diverse microorganisms inhabiting these plant hosts. This work has explored the potential of harnessing FEF communities as a method for controlling A. psidii in the critically endangered E. koolauensis. In this study, we tested the effect of a diverse microbial inoculum on inhibiting A. psidii infection in plants, demonstrating the potential of harnessing FEF communities for disease control in the conservation of endangered plants.

The leaf homogenate was the single treatment to significantly decrease A. psidii infection on E. koolauensis leaves. Although pustule formation was visible on many treated leaves, necrotic areas were smaller and less frequent (Fig. 2). There are many examples of complex microbial inoculums improving plant disease resistance better than individual inoculum (Niu et al. 2017; Santhanam et al. 2015; Wei et al. 2015; Zahn and Amend 2017). Use of a highdiversity inoculum has been shown to not only enhance beneficial microbe persistence but also effectively decrease disease incidence through intensified resource competition and pathogen inhibition, when compared with single-strain inoculums (Hu et al. 2015). However, some studies have shown that inoculum diversity is not necessarily related to disease resistance in plants and, in some cases, may even decrease the protective effects of the community (Becker et al. 2012; Berg and Koskella 2018; Rolli et al. 2015). In the case of this experiment, increased resistance to A. psidii may not be intrinsically caused by higher microbial diversity but, rather, by the increased probability of encountering key taxa in the diverse

TABLE 2

Average percent diseased leaf tissue (disease severity) for each treatment

\begin{tabular}{lccc}
\hline Treatment & $N^{\mathrm{a}}$ & $\mathrm{SD}^{\mathrm{b}}$ & Diseased tissue $^{\mathrm{c}}$ \\
\hline Rust Only & 12 & 0.249 & 0.544 \\
\hline No rust & 12 & 0.250 & $0.008^{* * *}$ \\
\hline Leaf homogenate & 12 & 0.384 & $0.197^{* *}$ \\
\hline Leaf homogenate + No FEF & 12 & 0.195 & $0.350^{*}$ \\
\hline C. rosea (Leaf) & 12 & 0.349 & $0.355^{*}$ \\
\hline C. rosea (Rust) & 12 & 0.265 & 0.406 \\
\hline B. ochroleuca & 12 & 0.161 & 0.498 \\
\hline Cladosporium spp. & 12 & 0.005 & 0.569 \\
\hline $\begin{array}{l}\text { a Number. } \\
\text { b Standard deviation. }\end{array}$ & & \\
c Area of diseased leaf tissue; & $* * *, * *$, and * indicate $P<0.001$, \\
O.01, and 0.1, respectively. & & \\
d FEF = foliar endophytic fungi. &
\end{tabular}


leaf homogenate. This makes sense in the context of the "portfolio" or "insurance" effect, where higher species richness provided by the leaf homogenate can serve as a statistical buffer toward biotic disruptions such as pathogen invasion (Doak et al. 1998; Tilman et al. 1998; Yachi and Loreau 1999). Reisolation of inocula, especially at various infection time points, will be useful for strengthening the association of introduced and established microbial taxa with variation in host disease resistance in later experiments. Although the exact mechanisms of disease reduction caused by the leaf homogenate treatment are unverified, our results highlight the advantages of
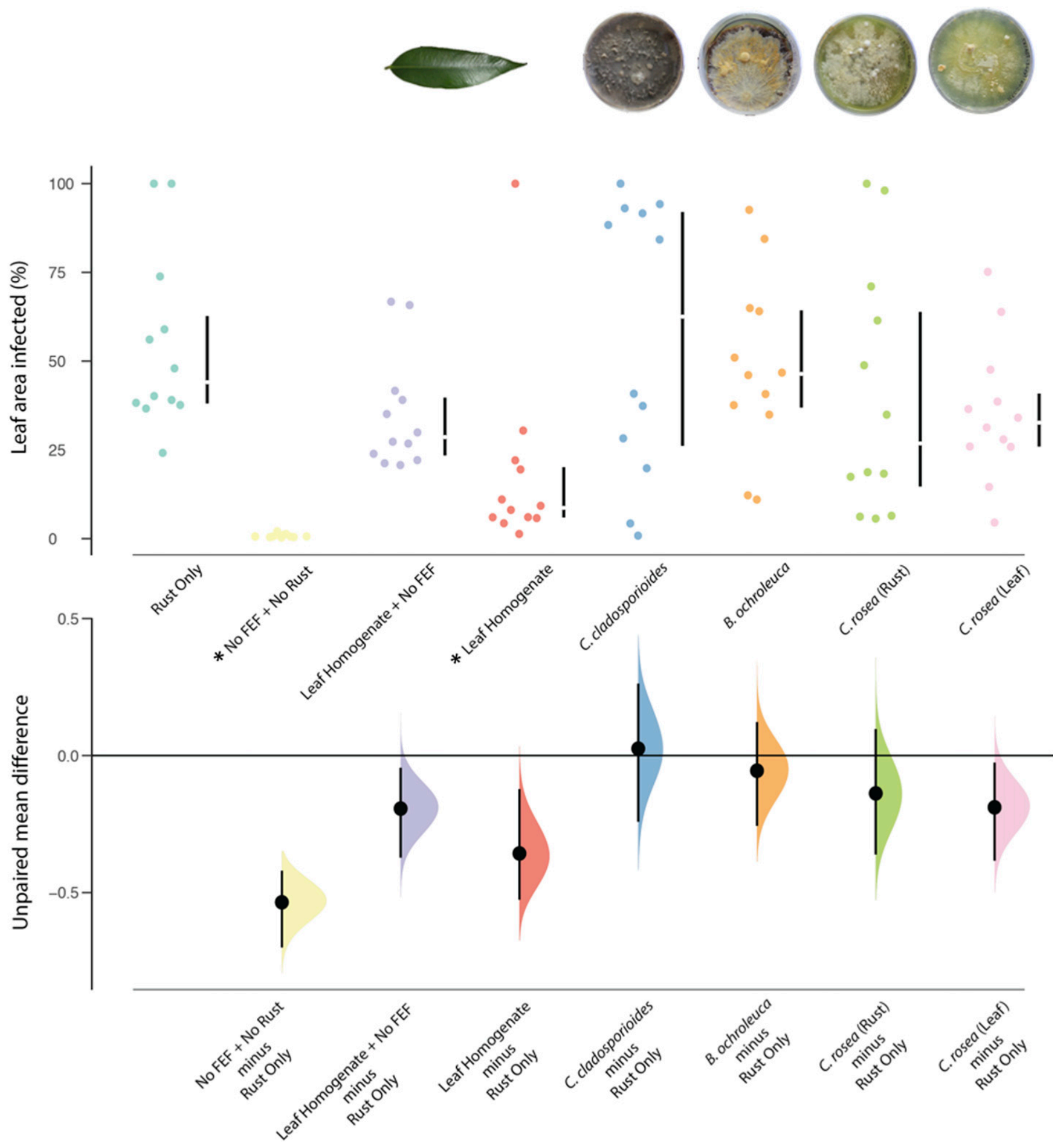

Fig. 2. Effect of leaf homogenate and foliar endophytic fungi (FEF) spore inoculation treatments on Austropuccinia psidii disease severity. In the upper panel, the raw data are plotted with disease severity represented by percent leaf area diseased with $A$. psidii pustules, urediniospores, and necrotic tissue. Treatments marked with an asterisk (*) denote a significant difference from the Rust Only treatment. In the lower panel, mean differences from the Rust Only treatment are plotted as bootstrap sampling distributions. Each mean difference is depicted as a dot. The 95\% confidence intervals are indicated by the ends of the black vertical error bars in both upper and lower panels. 
introducing a diverse FEF community, versus single-species inoculums, to effectively mediate disease resistance.

Future extensions of this work would greatly benefit from amplicon sequencing to not only characterize key taxa but also clarify the community networks within the pathosystem and leaf homogenate. It is now common knowledge that composition of a microbial community is as important as diversity in regard to the invasion success of pathogens and establishment of dispatched biocontrols (Erlacher et al. 2014; Podolich et al. 2015; Trivedi et al. 2012). Subtle alterations to the microbial community, abiotic environment, and host genotype can lead to significant shifts in microbiome structures and their ability to fight off disease (Agler et al. 2016; Bakker et al. 2014; Niu et al. 2017). It has been posited that the outcome of network interactions within the phytobiome may be largely dependent on a hierarchy of contingency rules where both genetic resistance and pathogen competition must be absent in order for FEF to inhibit disease successfully (Busby et al. 2019). The absence of host resistance is thought to remove a critical species filter, promoting greater colonization, diversity, niche overlap, and interspecific interactions of symbionts contributing to pathogen exclusion or inhibition (Skelton et al. 2016). If such contingency rules are generalizable across pathosystems, quantified virulence of A. psidii across various E. koolauensis genotypes may be helpful for evaluating the efficacy of future mycobiome transplants. Integration of biocontrol in endangered plant populations will rely on a robust microbial community and particular plant genotypes that cannot only inhibit pathogen establishment but also persist across diverse biotic and abiotic conditions.

Although this experiment and previous literature suggest that design and synthesis of future leaf homogenates should take a whole-community approach, there are many instances in which single taxa inoculants have been effective, at least under specific conditions. It is for this reason that FEF isolates used in this study were selected for leaf inoculation specifically for their antagonistic behavior, including hyperparisitism (Clonostachys rosea and Cladosporium cladosporioides), competitive exclusion (B. ochroleuca and $C$. cladosporioides), and induced systemic resistance ( $C$. cladosporioides). Specific antagonism toward $A$. psidii has been previously reported in Tuberculina, Verticillium, and Cladosporium spp., where disintegration of rust spore cell walls was observed (Moricca and Ragazzi 2008). dos Santos et al. (1998) observed reductions in A. psidii germination by single-isolate introductions of Bacillus subtilis. A study by Amorim et al. (1993) also found evidence of $A$. psidii hyperparasitism by the latent fungal pathogen Fusarium decemcellulare. In this study, SEM imaging of infected Rose apple (S. jambos) leaves revealed possible hyperparsitic activity within A. psidii pustules (Fig. 1). Clonostachys rosea's high prevalence in isolate collections and association with $A$. psidii rust pustules across plant species, as well its marginal decrease in disease severity $(P<0.1)$, may present itself as a future biocontrol component. $C$. rosea is a broad-spectrum mycoparasite that has been previously associated with the reduction of a number of plant pathogens (Borges et al. 2015; Cota et al. 2009; Jensen et al. 2004; Nobre et al. 2005; Rodríguez et al. 2011; Xue 2003; Xue et al. 2014). It may also be able to synergize with other beneficial fungi, as seen in a study by Keyser et al. (2016), where coinoculation with Metarhizium spp. had a greater effect on pathogen inhibition. Considering the diversity of $A$. psidii antagonism previously observed, it may be worth considering the integration of $A$. psidii antagonists such as $C$. rosea in future leaf homogenate treatments to further increase the efficacy of pathogen control.

In addition to fungi, plant processes are heavily influenced by other biotic and abiotic components of the phyllosphere (Hardoim et al. 2015; Lindow and Brandl 2003; Roossinck 2015). We tested to see whether these nonfungal components might be contributing to disease inhibition in the leaf homogenate treatment by filtering out particles larger than $2 \mu \mathrm{m}$ (Leaf homogenate + No FEF). We observed marginal disease inhibition from this treatment $(P<0.1)$, suggesting the possibility of nonfungal components contributing to disease resistance in the leaf homogenate. Bacteria and viruses play an essential role in community resistance to plant diseases and have been found to be more frequently involved in induced systemic responses when compared with their FEF counterparts (Kloepper and Ryu 2006). Additionally, chemical constituents derived from the leaf homogenate such as wax, cutin monomers, and other cuticle components may have operated as inhibitors to pathogen invasion within the leaf homogenate treatments (Ryan et al. 1986). Recent studies have demonstrated how differences in physical (e.g., cuticle wax density and incidences of wax plaques) and chemical signaling in Eucalyptus spp. leaf surfaces affect the capacity of A. psidii spores to recognize, adhere, and germinate on the leaf surface, ultimately increasing or decreasing plant resistance to A. psidii (dos Santos et al. 2019; Xavier et al. 2015). A study by Tessmann et al. (2001) found that hentriacontane, a compound derived from $S$. jambos leaf wax extract, can increase germination of $A$. psidii spores up to $88 \%$, making it an important factor to consider during A. psidii pathogenicity. This is interesting considering the increased resistance to $A$. psidii despite the use of $S$. jambos leaves for the leaf homogenate treatment in this study. Although leaf chemical compounds of the leaf homogenate treatment have not been verified in this study, it is interesting to speculate on the possible mechanisms in which hentriacontane and other leaf chemicals could be involved with $A$. psidii resistance during leaf homogenate application (e.g., mistimed A. psidii urediniospore germination, upregulation of local suppressive FEF, or chemically induced host response). Regardless, further studies will be necessary to determine whether the marginal inhibition observed by the Leaf homogenate + No FEF treatment is a product of FEF exclusion, dose dependency, both, or other unknown means. Understanding how chemical constituents, host genotype, and microbe-microbe interactions concurrently affect disease resistance will be important for understanding the basis of microbe-mediated plant health.

By utilizing a leaf homogenate application, this study demonstrates the potential of harnessing beneficial native microbes to increase plant pathogen resistance in a conservation context. Our study illustrates the importance of including a diverse phyllosphere microbiota over individual taxa inoculations for disease resistance due to a higher probability of encountering key beneficial taxa. Although the protection of E. koolauensis populations from A. psidii should be part of a holistic and integrative management approach, our findings demonstrate whole-leaf microbiome transplants as a powerful tool to enhance plant health and will be important for developing conservation strategies for critically endangered plants threatened by introduced disease.

\section{ACKNOWLEDGMENTS}

We thank K. Kawelo, M. Garma, and the staff at O'ahu Army Natural Resource Program (OANRP) for their collection and propagation of plant material for this study as well as their expertise in rare plant conservation; and the Amend laboratory and the Hynson laboratory for valuable feedback and comments on the manuscript.

\section{LITERATURE CITED}

Agler, M. T., Ruhe, J., Kroll, S., Morhenn, C., Kim, S. T., Weigel, D., and Kemen, E. M. 2016. Microbial hub taxa link host and abiotic factors to plant microbiome variation. PLoS Biol. 14:e1002352. 
Aly, A. H., Debbab, A., and Proksch, P. 2011. Fungal endophytes: Unique plant inhabitants with great promises. Appl. Microbiol. Biotechnol. 90:1829-1845.

Amorim, E. P. R., Pio-Ribeiro, G., Menezes, M., and Coelho, R. S. B. 1993. The pathogenicity and hyperparasitic action of Fusarium decemcellulare on Puccinia psidii in guava (Psidium guajava). Fitopatol. Bras. 18:226-229.

Arganda-Carreras, I., Kaynig, V., Rueden, C., Eliceiri, K. W., Schindelin, J., Cardona, A., and Seung, H. S. 2017. Trainable Weka Segmentation: A machine learning tool for microscopy pixel classification. Bioinformatics 33:2424-2426

Arnold, A. E., Mejia, L. C., Kyllo, D., Rojas, E. I., Maynard, Z., Robbins, N., and Herre, E. A. 2003. Fungal endophytes limit pathogen damage in a tropical tree. Proc. Natl. Acad. Sci. U.S.A. 100:15649-15654.

Bakker, M. G., Schlatter, D. C., Otto-Hanson, L., and Kinkel, L. L. 2014. Diffuse symbioses: Roles of plant-plant, plant-microbe and microbemicrobe interactions in structuring the soil microbiome. Mol. Ecol. 23:1571-1583.

Becker, J., Eisenhauer, N., Scheu, S., and Jousset, A. 2012. Increasing antagonistic interactions cause bacterial communities to collapse at high diversity. Ecol. Lett. 15:468-474.

Berg, M., and Koskella, B. 2018. Nutrient- and dose-dependent microbiomemediated protection against a plant pathogen. Curr. Biol. 28:24872492.e3.

Borges, Á. V., Saraiva, R. M., and Maffia, L. A. 2015. Biocontrol of gray mold in tomato plants by Clonostachys rosea. Trop. Plant Pathol. 40:71-76.

Boyd, I. L., Freer-Smith, P. H., Gilligan, C. A., and Godfray, H. C. J. 2013. The consequence of tree pests and diseases for ecosystem services. Science 342:1235773.

Busby, P. E., Crutsinger, G., Barbour, M., and Newcombe, G. 2019. Contingency rules for pathogen competition and antagonism in a genetically based, plant defense hierarchy. Ecol. Evol. 9:6860-6868.

Busby, P. E., Ridout, M., and Newcombe, G. 2016. Fungal endophytes: Modifiers of plant disease. Plant Mol. Biol. 90:645-655.

Busby, P. E., Soman, C., Wagner, M. R., Friesen, M. L., Kremer, J., Bennett, A., Morsy, M., Eisen, J. A., Leach, J. E., and Dangl, J. L. 2017. Research priorities for harnessing plant microbiomes in sustainable agriculture. PLoS Biol. 15:e2001793.

Carnegie, A. J., and Giblin, F. R. 2020. Austropuccinia psidii (myrtle rust). Invasive species compendium. https://www.cabi.org/isc/datasheet/45846

Carnegie, A. J., Kathuria, A., Pegg, G. S., Entwistle, P., Nagel, M., and Giblin, F. R. 2016. Impact of the invasive rust Puccinia psidii (myrtle rust) on native Myrtaceae in natural ecosystems in Australia. Biol. Invasions 18:127-144.

Carnegie, A. J., and Lidbetter, J. R. 2012. Rapidly expanding host range for Puccinia psidii sensu lato in Australia. Australas. Plant Pathol. 41:13-29.

Christian, N., Herre, E. A., Mejia, L. C., and Clay, K. 2017. Exposure to the leaf litter microbiome of healthy adults protects seedlings from pathogen damage. Proc. R. Soc. B 284:20170641.

Collado, J., Platas, G., Paulus, B., and Bills, G. F. 2007. High-throughput culturing of fungi from plant litter by a dilution-to-extinction technique. FEMS Microbiol. Ecol. 60:521-533.

Cota, L. V., Maffia, L. A., Mizubuti, E. S. G., and Macedo, P. E. F. 2009. Biological control by Clonostachys rosea as a key component in the integrated management of strawberry gray mold. Biol. Control 50:222-230.

Doak, D. F., Bigger, D., Harding, E. K., Marvier, M. A., O’Malley, R. E., and Thomson, D. 1998. The statistical inevitability of stability-diversity relationships in community ecology. Am. Nat. 151:264-276.

dos Santos, C. C. F., de Castro, H. A., Bettio, W., and Junior, A. A. 1998. In vitro sensibility of Puccinia psidii urediniospores to Bacillus subtilis. Summa Phytopathol. 24:183-185.

dos Santos, I. B., Lopes, M. da S., Bini, A. P., Tschoeke, B. A. P., Verssani, B. A. W., Figueredo, E. F., Cataldi, T. R., Marques, J. P. R., Silva, L. D., Labate, C. A., and Quecine, M. C. 2019. The Eucalyptus cuticular waxes contribute in preformed defense against Austropuccinia psidii. Front. Plant Sci. 9:1978.

Ellstrand, N. C., and Elam, D. R. 1993. Population genetic consequences of small population size: Implications for plant conservation. Annu. Rev. Ecol. Evol. Syst. 24:217-242.

Erlacher, A., Cardinale, M., Grosch, R., Grube, M., and Berg, G. 2014. The impact of the pathogen Rhizoctonia solani and its beneficial counterpart Bacillus amyloliquefaciens on the indigenous lettuce microbiome. Front. Microbiol. 5:175.

Filonow, A. B., Vishniac, H. S., Anderson, J. A., and Janisiewicz, W. J. 1996. Biological control of botrytis cinereain apple by yeasts from various habitats and their putative mechanisms of antagonism. Biol. Control 7:212-220.

Frankham, R. 2003. Genetics and conservation biology. C. R. Biol. 326:22-29.

Gardes, M., and Bruns, T. D. 1993. ITS primers with enhanced specificity for Basidiomycetes-application to the identification of mycorrhizae and rusts. Mol. Ecol. 2:113-118.

Glen, M., Alfenas, A. C., Zauza, E. A. V., Wingfield, M. J., and Mohammed, C. 2007. Puccinia psidii: A threat to the Australian environment and economy-A review. Australas. Plant Pathol. 36:1-16.

Gurevitch, J., and Hedges, L. V. 2001. Meta-analysis: Combining the results of independent studies in experimental ecology. Pages 347-369 in: The Design and Analysis of Ecological Experiments. S. Scheiner and J. Gurevitch, eds. Oxford University Press, New York, NY, U.S.A.

Hardoim, P. R., Van Overbeek, L. S., Berg, G., Pirttilä, A. M., Compant, S., Campisano, A., Döring, M., and Sessitsch, A. 2015. The hidden world within plants: Ecological and evolutionary considerations for defining functioning of microbial endophytes. Microbiol. Mol. Biol. Rev. 79:293-320.

Heydari, A., and Pessarakli, M. 2010. A review on biological control of fungal plant pathogens using microbial antagonists. J. Biol. Sci. 10:273-290.

Ho, J., Tumkaya, T., Aryal, S., Choi, H., and Claridge-Chang, A. 2019. Moving beyond $P$ values: Data analysis with estimation graphics. Nat. Methods 16:565-566.

Høyer, A. K., Jørgensen, H. J. L., Jensen, B., Murphy, B. R., and Hodkinson, T. R. 2019. Emerging methods for biological control of barley diseases including the role of endophytes. Pages 93-113 in: Endophytes for a Growing World. T. R. Hodkinson, F. M. Doohan, M. J. Saunders, and B. R. Murphy, eds. Cambridge University Press, Cambridge, U.K.

Hu, J., Wei, Z., Friman, V.-P., Gu, S.-h., Wang, X.-f., Eisenhauer, N., Yang, T.-j., Ma, J., Shen, Q.-r., Xu, Y.-c., and Jousset, A. 2015. Probiotic diversity enhances rhizosphere microbiome function and plant disease suppression. MBio 7:e01790-16.

Iriondo, J. M., Maxted, N., and Dulloo, M. E., eds. 2008. Conserving Plant Genetic Diversity in Protected Areas: Population Management if Crop Wild Relatives. CABI, Wallingford, U.K.

Jensen, B., Knudsen, I. M. B., Madsen, M., and Jensen, D. F. 2004. Biopriming of infected carrot seed with an antagonist, Clonostachys rosea, selected for control of seedborne Alternaria spp. Phytopathology 94:551-560.

Junghans, D. T., Alfenas, A. C., Brommonschenkel, S. H., Oda, S., Mello, E. J., and Grattapaglia, D. 2003. Resistance to rust (Puccinia psidii Winter) in Eucalyptus: Mode of inheritance and mapping of a major gene with RAPD markers. Theor. Appl. Genet. 108:175-180.

Karlsson, I., Friberg, H., Steinberg, C., and Persson, P. 2014. Fungicide effects on fungal community composition in the wheat phylloshpere. PLoS One 9:e111786.

Keir, M. 2018. Eugenia koolauensis. The IUCN Red List of Threatened Species 2018.

Keyser, C. A., Jensen, B., and Meyling, N. V. 2016. Dual effects of Metarhizium spp. and Clonostachys rosea against an insect and a seedborne pathogen in wheat. Pest Manage. Sci. 72:517-526.

Kloepper, J. W., and Ryu, C. M. 2006. Bacterial endophytes as elicitors of induced systemic resistance. Pages 33-52 in: Microbial root endophytes. B. J. E. Schulz, C. J. C. Boyle, and T. N. Sieber, eds. Springer-Verlag, Berlin, Germany.

Langrell, S. R. H., Glen, M., and Alfenas, A. C. 2008. Molecular diagnosis of Puccinia psidii (guava rust)-A quarantine threat to Australian eucalypt and Myrtaceae biodiversity. Plant Pathol. 57:687-701.

Lindow, S. E., and Brandl, M. T. 2003. Microbiology of the phyllosphere. Appl. Environ. Microbiol. 69:1875-1883.

Loope, L. 2010. A summary of information on the rust Puccinia psidii Winter (guava rust) with emphasis on means to prevent introduction of additional strains to Hawaii. U.S. Geological Survey Open-File Report 2010-1082.

Loope, L., Uchida, J., and Mehrhoff, L. 2008. The threat of the non-native neotropical rust Puccinia psidii to Hawaiian biodiversity and native ecosystems: A case example of the need for prevention. Proc. 2007 GWS Biennial Conf. Parks, Protected Areas, and Cultural Sites. The George Wright Society, Hancock, MI, U.S.A.

Moricca, S., and Ragazzi, A. 2008. Biological and integrated means to control rust diseases. Pages 303-329 in: Integrated Management of Diseases caused by Fungi, Phytoplasma and Bacteria. A. Ciancio and K. Mukerji, eds. Integrated Management of Plant Pests and Diseases, vol. 3. Springer, Dordrecht, The Netherlands. 
Moricca, S., Ragazzi, A., and Assante, G. 2005. Biocontrol of rust fungi by Cladosporium tenuissimum. Pages 213-230 in: Rust Diseases of Willow and Poplar. M. H. Pei and A. R. McCracken, eds. CABI, Wallingford, U.K.

Newhouse, A. E., Polin-McGuigan, L. D., Baier, K. A., Valletta, K. E., Rottmann, W. H., Tschaplinski, T. J., Maynard, C. A., and Powell, W. A. 2014. Transgenic American chestnuts show enhanced blight resistance and transmit the trait to T1 progeny. Plant Sci. 228:88-97.

Niu, B., Paulson, J. N., Zheng, X., and Kolter, R. 2017. Simplified and representative bacterial community of maize roots. Proc. Natl. Acad. Sci. U.S.A. 114:E2450-E2459.

Nobre, S. A. M., Maffia, L. A., Mizubuti, E. S. G., Cota, L. V., and Dias, A. P. S. 2005. Selection of Clonostachys rosea isolates from Brazilian ecosystems effective in controlling Botrytis cinerea. Biol. Control 34:132-143.

O’Hanlon, K. A., Knorr, K., Jørgensen, L. N., Nicolaisen, M., and Boelt, B. 2012. Exploring the potential of symbiotic fungal endophytes in cereal disease suppression. Biol. Control 63:69-78.

Paradis, E., and Schliep, K. 2019. ape 5.0: An environment for modern phylogenetics and evolutionary analyses in R. Bioinformatics 35:526-528.

Parratt, S. R., and Laine, A. L. 2016. The role of hyperparasitism in microbial pathogen ecology and evolution. ISME J. 10:1815-1822.

Pegg, G. S., Lee, D. J., and Carnegie, A. J. 2018. Predicting impact of Austropuccinia psidii on populations of broad leaved Melaleuca species in Australia. Australas. Plant Pathol. 47:421-430.

Podolich, O., Ardanov, P., Zaets, I., Pirttilä, A. M., and Kozyrovska, N. 2015. Reviving of the endophytic bacterial community as a putative mechanism of plant resistance. Plant Soil 388:367-377.

R Core Team. 2013. R: A Language and Environment for Statistical Computing. R Foundation for Statistical Computing, Vienna, Austria. http://www.R-project.org/

Rodríguez, M. A., Cabrera, G., Gozzo, F. C., Eberlin, M. N., and Godeas, A 2011. Clonostachys rosea BAFC3874 as a Sclerotinia sclerotiorum antagonist: Mechanisms involved and potential as a biocontrol agent. J. Appl. Microbiol. 110:1177-1186.

Rolli, E., Marasco, R., Vigani, G., Ettoumi, B., Mapelli, F., Deangelis, M. L., Gandolfi, C., Casati, E., Previtali, F., Gerbino, R., Cei, F. P., Borin, S., Sorlini, C., Zocchi, G., and Daffonchio, D. 2015. Improved plant resistance to drought is promoted by the root-associated microbiome as a water stress-dependent trait. Environ. Microbiol. 17:316-331.

Roossinck, M. J. 2015. Move over, bacteria! Viruses make their mark as mutualistic microbial symbionts. J. Virol. 89:6532-6535.

Roy, B. A., Alexander, H. M., Davidson, J., Campbell, F. T., Burdon, J. J., Sniezko, R., and Brasier, C. 2014. Increasing forest loss worldwide from invasive pests requires new trade regulations. Front. Ecol. Environ. 12:457-465.

Ryan, C. A., Bishop, P. D., Graham, J. S., Broadwy, R. M., and Duffey, S. S. 1986. Plant and fungal cell wall fragments activate expression of proteinase inhibitor genes for plant defense. J. Chem. Ecol. 12:1025-1036.

Santhanam, R., Luu, V. T., Weinhold, A., Goldberg, J., Oh, Y., and Baldwin, I. T. 2015. Native root-associated bacteria rescue a plant from a suddenwilt disease that emerged during continuous cropping. Proc. Natl. Acad. Sci. U.S.A. 112:E5013-E5020.

Schulz, B., Wanke, U., Draeger, S., and Aust, H. J. 1993. Endophytes from herbaceous plants and shrubs: Effectiveness of surface sterilization methods. Mycol. Res. 97:1447-1450.

Sievers, F., Wilm, A., Dineen, D., Gibson, T. J., Karplus, K., Li, W., Lopez, R., McWilliam, H., Remmert, M., Söding, J., Thompson, J. D., and Higgins, D. G. 2011. Fast, scalable generation of high-quality protein multiple sequence alignments using Clustal Omega. Mol. Syst. Biol. 7:539.
Skelton, J., Doak, S., Leonard, M., Creed, R. P., and Brown, B. L. 2016. The rules for symbiont community assembly change along a mutualism-parasitism continuum. J. Anim. Ecol. 85:843-853.

Soewarto, J., Giblin, F., and Carnegie, A. J. 2019. Austropuccinia psidii (myrtle rust) global host list, version 2. Australian Network for Plant Conservation, Canberra, ACT, Australia. https://www.anpc.asn.au/myrtle-rust

Stewart, J. E., Ross-Davis, A. L., Graça, R. N., Alfenas, A. C., Peever, T. L., Hanna, J. W., Uchida, J. Y., Hauff, R. D., Kadooka, C. Y., Kim, M.-S., Cannon, P. G., Namba, S., Simeto, S., Pérez, C. A., Rayamajhi, M. B., Lodge, D. J., Arguedas, M., Medel-Ortiz, R., López-Ramirez, M. A., Tennant, P., Glen, M., Machado, P. S., McTaggart, A. R., Carnegie, A. J., and Klopfenstein, N. B. 2017. Genetic diversity of the myrtle rust pathogen (Austropuccinia psidii) in the Americas and Hawaii: Global implications for invasive threat assessments. For. Pathol. 48:e12378.

Tessmann, D. J., Dianese, J. C., Miranda, A. C., and Castro, L. C. R. 2001. Epidemiology of a neotropical rust (Puccinia psidii): Periodical analysis of the temporal progress in a perennial host (Syzygium jambos). Plant Pathol. 50:725-731.

Tilman, D., Lehman, C. L., and Bristow, C. E. 1998. Diversity-stability relationships: Statistical inevitability or ecological consequence? Am. Nat. 151:277-282.

Trivedi, P., He, Z., Van Nostrand, J. D., Albrigo, G., Zhou, J., and Wang, N. 2012. Huanglongbing alters the structure and functional diversity of microbial communities associated with citrus rhizosphere. ISME J. 6:363-383.

U.S. Fish and Wildlife Service. 2011. Endangered and Threatened Wildlife and Plants; Listing 23 Species on Oahu as Endangered and Designating Critical Habitat for 124 species. Federal Register 76. https://www.govinfo. gov/content/pkg/FR-2011-08-02/pdf/2011-17162.pdf

Waterhouse, A. M., Procter, J. B., Martin, D. M. A., Clamp, M., and Barton, G. J. 2009. Jalview Version 2-a multiple sequence alignment editor and analysis workbench. Bioinformatics 25:1189-1191.

Wei, Z., Yang, T., Friman, V.-P., Xu, Y., Shen, Q., and Jousset, A. 2015. Trophic network architecture of root-associated bacterial communities determines pathogen invasion and plant health. Nat. Commun. 6:8413.

Wickham, H. 2009. ggplot2: Elegant Graphics for Data Analysis. SpringerVerlag, New York, NY, U.S.A.

Wingfield, M. J., Brockerhoff, E. G., Wingfield, B. D., and Slippers, B. 2015. Planted forest health: The need for a global strategy. Science 349:832-836.

Xavier, A. A., Costa, A., Mauro, L., Matsuoka, K., Hodges, C. S., and Alfenas, A. C. 2015. Infection process of Puccinia Psidii in Eucalyptus grandis leaves of different ages. Trop. Plant Pathol. 40:318-325.

Xue, A. G. 2003. Biological control of pathogens causing root rot complex in field pea using Clonostachys rosea strain ACM941. Phytopathology 93:329-335.

Xue, A. G., Chen, Y., Voldeng, H. D., Fedak, G., Savard, M. E., and Langle, T. 2014. Concentration and cultivar effects on efficacy of CLO-1 biofungicide in controlling Fusarium head blight of wheat. Biol. Control 73:2-7.

Yachi, S., and Loreau, M. 1999. Biodiversity and ecosystem productivity in a fluctuating environment: The insurance hypothesis. Proc. Natl. Acad. Sci. U.S.A. 96:1463-1468.

Yu, G., Smith, D., Zhu, H., Guan, Y., and Lam, T. T. 2017. ggtree: An R package for visualization and annotation of phylogenetic trees with their covariates and other associated data. Methods Ecol. Evol. 8:28-36.

Zahn, G., and Amend, A. S. 2017. Foliar microbiome transplants confer disease resistance in a critically endangered plant. PeerJ 5:e4020.

Zhong, S., Yang, B., and Puri, K. D. 2011. Characterization of Puccinia psidii isolates in Hawaii using microsatellite DNA markers. J. Gen. Plant Pathol. 77:178-181. 